\title{
Free Education Policy and Trade Liberalization: Consequences on Child and Adult Labour Markets in a Small Open Economy
}

\author{
Sarbajit Chaudhuri and Ujjaini Mukhopadhyay \\ University of Calcutta
}

\begin{abstract}
The paper purports to examine the implications of a free education policy and trade liberalization on the child and adult labour markets in the set-up of a Harris-Todaro type general equilibrium model. It has been found that a hike in the education subsidy or an inflow of foreign capital may produce counterproductive results on the supply of child labour in the urban area. Moreover, these policies may raise the level of urban unemployment of adult labour even when two types of labour are not substitutes to each other. The average income of the urban poor families may also decrease as a consequence.

- JEL Classifications: F10, J10, J13, I28.

- Key words: Child labour, Urban unemployment of adult labour, General equilibrium, Education subsidy, Trade liberalization.
\end{abstract}

\section{Introduction}

Child labour had been prevalent from as early as eighteenth century (mainly in rural farming) and gained a boost during the industrial revolution in the last century. In the past 50 years, the magnitude of child labour has been declining throughout the world, with the developed countries succeeding to completely eradicate the problem. Today, child labour is a phenomenon pervasive only in the transitional societies of the developing economies. It was only after globalization

\footnotetext{
*Corresponding address: Dr. Sarbajit Chaudhuri, 23 Dr. P.N. Guha Road, Belgharia, Kolkata 700083, India. Tel: 91-33-541-0455 (R), 91-33-557-5082 (C.U.) Fax: 91-33-844-1436 E-mails: sarbajitch@yahoo.com, s_jit@vsnl.net http://papers.ssrn.com/author = 294419

(C2003-Center for International Economics, Sejong Institution, All Rights Reserved.
} 
that the problem of child labour drew serious cognizance and called for different policy measures to curb the malpractice.

An accurate measure of working children is difficult to obtain since there is no single, clear-cut definition of child labour under international law. Usually most of the empirical surveys classify as 'child labour' those children under 12 years of age, who work on a regular basis for which they are paid or that results in output destined for the market (Basu, 1999). According to the Bureau of Statistics of the ILO, in 1995 at least 120 million of the world's children between the ages of 5 and 14 did full-time paid work. The participation rates for children aged between 10 to 14 years in 1995 was 13.02 for the world as a whole, and 14.37 for India, in particular.(Source: ILO, 1996). Although the estimates are satisfactory if compared with the 1950 estimates of 27.57 and 35.43 respectively, the magnitude of child labour in absolute terms is quite alarming. If the invisible workers who perform unpaid and household jobs are included, the estimates are likely to shoot up significantly.

In the conventional literature, the supply of child labour has been attributed to factors such as failure of the educational system, the objectives of households to maximize present income, a dualistic economy characteristic of developing countries with the co-existence of formal and informal sectors, etc. However, it is beyond any doubt that the root cause is abject poverty, which compels children to go out in the job market and earn their own means of livelihood. Policy prescriptions directed towards poverty alleviation are difficult to be implemented properly due to various bottlenecks and vicious circles typical of developing economies; even if implemented, they take a long time to mitigate the problem, so that legal restrictions can be more instrumental to deal with child labour. Legislative fiats to combat child labour range from an outright ban on child labour to social labeling of products. However, a total ban would be counterproductive in the sense that it may adversely affect the welfare of the poor households and force the children to take resort to more hazardous and illegal activities. Moreover, most of the children work in domestic service or informal sector, where labour law enforcement is virtually absent. Social labeling can be applied only to a few products (mostly exported ones), so that the potential effect is limited; it is also difficult to monitor the labeling operations and may have disastrous 
consequences on the developing economies as the recent Bangladeshi experience ${ }^{1}$ has shown. It is believed that the betterment of educational opportunities and a policy of compulsory education can more effectively remove children from work. Motivated by a desire to reduce both current and future poverty, cash or in-kind transfers targeted to poor families -but conditional on their offspring staying at school- have recently become popular in developing countries. If there is substitution between child labor and schooling then such programs are expected to reduce child labour (see Ravallion and Wodon 1999). ${ }^{2}$

In the recent theoretical literature on child labour the notable contributors are Eswaran (1996), Basu and Van (1998), and Dessy (2000). Eswaran (1996) has suggested improvement in healthcare services and legislation of compulsory education to eradicate child labour from the system. Basu and Van (1998) has shown that if child labour and adult labour are substitutes (substitution axiom) and if child labour is a luxury commodity to the poor households (luxury axiom), unfavourable adult labour markets, responsible for low adult wage rate, is the driving force behind the incidence of child labour. Thus labour market interventions that raise adults' wages are expected to mitigate the problem of child labour. In a more recent paper, Dessy (2000) has also advocated in favour of imposition of compulsory education as a means to combat the incidence of child labour.

The existing theoretical literature on child labour does not deal with issues like the supply of child labour and its linkages with the adult labour markets in a multi-sector general equilibrium framework. Neither we do find any work where the effects of education subsidy on the supply of child labour and its welfare are studied although the traditional wisdom recommends a hike in educational opportunities to eradicate the problem. Also no attempt has been made so far to analyze the implications of the liberalized trade policies like

\footnotetext{
${ }^{1}$ Owing to the possibility of introduction of the US Harkins Bill, which calls for complete ban on imports of any good that were manufactured wholly or partly by child workers, the employers in the booming garments industry in Bangladesh that had employed a large number of child labourers began removing the child workers drastically. The consequence was a chaotic process that left many children worse off than they had before. (Anti-slavery Reporter, 1996).
}

${ }^{2}$ See footnotes 11 and 15 in this context. 
inflow of foreign capital or removal of tariff restriction on the child labour market and on the problem of urban unemployment of adult labour. The latter is an important issue because the incidence of child labour is often cited as one of the prime factors responsible for the widespread prevalence of open unemployment in the adult labour market. This view is acceptable only when these types of labour are substitutes. On the contrary, when these two are complementary at least in some of the sectors of the economy, the validity of this argument is questionable.

The present paper is purported to examine the implications of an education subsidy policy and liberalized trade policies on the child labour market in a general equilibrium set-up. We build up a 3-sector Harris-Todaro model with urban unemployment. The economy is broadly divided into a rural and an urban sector. The latter consists of an informal sector and a formal sector. The rural sector produces an exportable commodity, while the informal sector produces a non-traded intermediary for the formal sector, which is the tariff protected import-competing sector. Child labour is used in the rural and informal sectors but it is assumed that the rural activities are perfectly substitutable between adult and child labour (see Basu (1999)) so that no separate market for child labour is considered in the rural sector. We show that an increase in the subsidy on education and/or foreign capital inflow accentuate the incidence of child labour in the urban sector. More importantly these policies tend to aggravate the urban unemployment problem of adult labour even though adult and child labours are not substitutes in the two urban sub-sectors. We then go on to analyze the effects of the free education policy and the different liberalized trade policies on the welfare of the poorer working families of the urban sector. We find that all these policies excepting the one of foreign capital inflow lower the welfare of the poor urban families. These results are important especially when the provision of free education policy and trade liberalization are often recommended for eradicating the problems of child labour and poverty in the developing economies.

\section{The Model}

We consider a small open monetised dual economy, which is broadly divided into an urban sector and a rural sector. The urban sector is subdivided 
into two sub-sectors-the urban informal sector and the urban formal sector- so that there are three sectors in the economy. The rural sector produces an agricultural product $X$, with the help of labour, both adult and child, and capital. Following Basu (1999), we make the assumption of 'substitution' in the rural sector, which suggests that adult labour is a substitute for child labour, or more generally, adults can do what children do. The rural sector is concerned mainly with activities relating to cultivation. For no such activities are children essential, so that adults can always replace them. Thus the substitution axiom is quite relevant in the rural sector. It is assumed that a child's labour is equivalent to $\beta$ units of an adult's labour, where $0<\beta<1$. In other words, each adult, working all day produces I unit of labour, whereas each child, working all day, produces units of labour. Thus, adult and child labour are perfect substitutes subject to an adult-equivalent scale correction of $\beta$. The adult labour earns an institutionally given rural wage ${ }^{3}$ of $\overline{\mathrm{W}}_{X}$, while a child labour earns $\beta \overline{\mathrm{W}}_{X}$. The rigidity of rural wage can be justified ${ }^{4}$ by the Efficiency Wage Hypothesis or the Collusive Theory of unemployment (Osmani 1990).

The informal sector uses adult labour, child labour, and capital to produce an

\footnotetext{
${ }^{3}$ An exogenously given rural wage for adult labour does not give rise to the possibility of rural unemployment of adult labour as we have considered a Harris-Todaro type economy. The levels of production and employment of labour in the rural sector (in other sectors of the economy as well) are determined by factor endowments, technological and other parameters of the system. Those adult workers who are unable to find employment in the rural sector migrate to the urban sector with their children as both adult and child wage rates in the urban informal sector are absolutely flexible. The complete flexibility of informal sector wage rates leads to the equality between the expected urban income for a prospective rural migrant family and their actual family income in the rural sector (given by equation (7)). In a completely different context, Gupta (1994) has also made the same assumption and explained the simultaneous existence of informal sector and open unemployment in the urban area.

${ }^{4}$ According to the 'wage efficiency hypothesis', the nutritional efficiencies of the workers are positively related to their respective wage incomes (at least for some minimum levels). Thus the employers in the rural labour market would prefer to pay efficiency wages to their respective workers rather than lower wages even if there is excess supply in the labour market. In this situation, competition would fail to lower the wage rates and clear the labour market. For surveys of the nutritional evidence from the perspective of economics one can look at Dasgupta and Ray (1990) and Osmani (1990). On the other hand, Osmani (1991) has observed that in the casual labour market in the rural areas, workers generally refuse to undercut other workers, even if they are unemployed, for fear that this would lower wages for everybody at present and in the future. In other words, they may prefer to remain unemployed in the hope that in the next period they would find employment at the prevailing high wage rates. Thus, the wage rates would not fall even when there is open unemployment in the labour market. Similar evidence is also found in Rudra (1981) and Dreze and Mukherjee (1989).
} 
internationally non-traded intermediary ${ }^{5}$, Y, for the formal sector. Many of the large industries like the carpet weaving industries, the glass manufacturing industries, the bangles industries, leather bag and shoe manufacturing industries, garment industries, etc. have split up into tiny units and shifted the production process to urban slum, in order to utilize the services of children at lower wages. Some among these industries give subcontract to enterprises, which produce a component of the formal sector output, on an informal basis, hiring child labour. For most of these industries, child labour is essential since their 'nimble fingers' are typically suited to perform activities like carpet weaving, stitching buttons, etc. Hence, we consider a separate child labour market in this sector, with perfectly flexible wage rate $\mathrm{W}_{\mathrm{C}}$. The informal sector adult wage rate is $\mathrm{W}_{\mathrm{Y}}$ and quite obviously, $\mathrm{W}_{\mathrm{C}}<\mathrm{W}_{\mathrm{Y}}$.

The formal sector is the tariff protected, capital-intensive import-competing sector producing manufactured good, $Z$. It uses adult labour, capital and produced input from the informal sector. Owing to effective wage legislation and unionization of labour, there is rigidity of wages, so that $\overline{\mathrm{W}}_{z}$ is given exogenously. Throughout the paper we shall assume that the urban sector, as a whole is more capital-intensive than the rural sector, which is quite common in the literature of the informal sector (e.g. see Chandra and Khan (1993)).

There is homogeneity of labour so that each adult worker has exactly -number of potential child worker at his disposal and without any loss of generality we can choose $\alpha=1$. So, each working family comprises of one adult and one child worker each. Production functions ${ }^{6}$ are of fixed coefficient type; markets are competitive; capital is fully employed and is completely mobile among the three sectors. There is presence of Harris-Todaro type of adult unemployment, while child labour is assumed to be fully employed ${ }^{7}$. We assume that a child worker

\footnotetext{
${ }^{5}$ Empirical evidence suggests that the informal sector units mostly produce intermediate inputs for the formal sector. See for example, Joshi and Joshi (1976), Bose (1978), Papola (1981) and Romatet (1983). However, there are a few theoretical papers like Grinols (1991), Chandra and Khan (1993) and Gupta (1997), which formalize the urban informal sector as an internationally traded final good-producing sector.

${ }^{6}$ This is a simplifying assumption. Since all the three sectors use more than two inputs in production, unless fixed-coefficient technologies are assumed, the algebra of the model will be seriously complicated by the presence of partial elasticities of substitutions when one considers the effects of any changes in the price system. This point has been further taken up in the concluding section of the paper.

${ }^{7}$ Complete flexibility of the wage rate of child labour ensures full-employment of child labour in the urban sector.
} 
cannot migrate ${ }^{8}$ to the urban sector unless his guardian migrates. In other words, migration of an adult worker is always accompanied by migration of the child worker in his family. The rural and urban adult and child wage rates are related by the migration equilibrium condition where the wage income of a rural working family is equal to the expected urban wage, consisting of expected urban adult wage and child labour wage rate. Owing to the small open economy assumption, prices of the traded goods, $X$ and $Z$ are given internationally. Since $Y$ is non-traded its price is endogenously determined by the demand-supply mechanism-the supply of $Y$ is constrained by the demand for $Y$ in the formal sector.

The following symbols will be used in the formal presentation of the model:

$\mathrm{a}_{\mathrm{Li}}$ : labour-output ratio in the $i$-th sector, $i=X, Y, Z$;

$\mathrm{a}_{\mathrm{CY}}$ : child labour-output in the ratio $Y$ sector;

$\mathrm{a}_{\mathrm{Ki}}$ : capital-output ratio in the $i$-th sector, $i=X, Y, Z$;

$\mathrm{a}_{\mathrm{YZ}}$ : requirement of $\mathrm{Y}$ to produce one unit of $Z$;

$\mathrm{P}_{\mathrm{i}}$ : world price of the $i$-th good, $i=X, Z$;

$t$ : ad-valorem tariff rate on the import of $Z$;

$P_{Y}:$ domestically determined price of $Y$;

$W_{Y}$ : adult wage rate in the informal sector;

$W_{C}$ : child wage rate;

$\overline{\mathrm{W}}_{i}$ : institutionally given wage rates in the $i$-th sectors, $i=X, Z$;

$r$ : rate of return to capital;

$L$ : total adult labour endowment;

$\mathrm{L}_{\mathrm{C}}$ : supply of child labour;

$K$ : fixed stock of capital in the economy;

$L_{U}$ : level of unemployment of adult labour in the urban sector;

$E$ : amount of subsidy on education.

A general equilibrium of the system is given by the following set of equations:

$$
\begin{aligned}
& \overline{\mathrm{W}}_{\mathrm{X}} \mathrm{a}_{\mathrm{LX}}+\mathrm{ra}_{\mathrm{KX}}=\mathrm{P}_{\mathrm{X}}, \\
& \mathrm{W}_{\mathrm{C}} \mathrm{a}_{\mathrm{CY}}+\mathrm{W}_{\mathrm{Y}} \mathrm{a}_{\mathrm{LY}}+\mathrm{ra}_{\mathrm{KY}}=\mathrm{P}_{\mathrm{Y}} \text {, }
\end{aligned}
$$

\footnotetext{
${ }^{8}$ This is not true in general. In some cases the children who especially work in the informal service sector of the urban area migrate without the other members of their families. Besides there may be many cases where adult members of rural families come to the urban areas for work without their offspring. However, there is some empirical evidence in support of our assumption (see Mohsin 1996).
} 


$$
\begin{gathered}
\mathrm{P}_{\mathrm{Y}} \mathrm{a}_{\mathrm{YZ}}+\overline{\mathrm{W}}_{Z} \mathrm{a}_{\mathrm{LZ}}+\mathrm{ra}_{\mathrm{KZ}}=\mathrm{P}_{\mathrm{Z}}(1+\mathrm{t}), \\
\frac{\mathrm{a}_{L X} \mathrm{X}}{(1+\beta)}+\mathrm{a}_{L Y} \mathrm{Y}+\mathrm{a}_{L Z} \mathrm{Z}+\mathrm{L}_{U}=\mathrm{L} \\
\mathrm{a}_{\mathrm{CY}} \mathrm{Y}=\mathrm{L}_{\mathrm{C}} \\
a_{K X} X+a_{K Y} Y+a_{K Z} Z=K,
\end{gathered}
$$

Equations (1)-(3) are the usual price-unit cost equality conditions in the three sectors of the economy. Equations (5) and (6) are the full employment conditions of child labour and capital, respectively. Equation (4) is the endowment equation of adult labour. In equation (4) $\left(a_{L X} \cdot X /(1+\beta)\right)$ is the number of adult workers (or working families) employed in the rural sector. This is because one working family, consisting of one adult and one child worker each, is equivalent to $(1+\beta)$ units of adult labourers.

The Harris-Todaro migration equilibrium condition is given by

$$
\frac{W_{Y} a_{L Y} Y+\bar{W}_{Z} a_{L Z} Z}{a_{L Y} Y+a_{L Z} Z+L_{U}}+W_{C}=\bar{W}_{X}(1+\beta)
$$

The right-hand side of (7) is the total income of a working family in the rural sector, which must be equal to the expected total income of the family in the urban sector (the left-hand side) in migration equilibrium ${ }^{9}$.

The supply of child labour in the urban sector ${ }^{10}$ is given by

$$
L_{C}=a_{L Y} Y+L_{U}-f(E),
$$

where $f(E)$ is the number of school-going children from the poorer section of the urban sector, with $f^{\prime}>0$. This relationship can be explained as follows. Abject

\footnotetext{
${ }^{9}$ A typical Harris-Todaro model with urban unemployment fails to provide a satisfactory answer to the questions as to how the unemployed workers persevere having no income at all. It is supposed that they survive as social parasites on the earnings of their employed counterparts. Fortunately, the present paper furnishes a more acceptable answer to the above question. It explains that the offspring who find no problem to be absorbed in the urban informal sector take up the responsibility to feed their unemployed guardians and this case is common in the developing countries.

${ }^{10} \mathrm{We}$ in this paper assume that no children in the rural sector goes to schools. This is not totally unrealistic because in the rural sector of the developing countries the very availability of educational opportunities is extremely limited.
} 
poverty and lack of educational facilities are claimed to be the two most important factors responsible for the persistence of child labour. If one admits the luxury axiom of Basu and Van (1998) there is enough justification to assume that a household would not send its children out to work if their incomes from non-child labour sources are sufficiently high. In the urban sector of the economy in our model, each worker employed in the formal sector earns relatively high contractual wage, $\bar{W}_{Z}$, while the labourers in the urban informal sector earn low wage incomes and the unemployed adult workers have no income at all. So it would be justified to assume that the last two categories of workers in the urban sector send their children out to work to supplement their low-income levels from non-child labour sources. Thus the higher the number of labourers in these two categories, the larger would be the potential supply of child labour. As per our assumption that each adult worker has exactly one child in his family, the number of potential child workers in the urban area will be $\left(a_{L Y} Y+L_{U}\right)$. To get the actual supply of child labour one has to deduct the number of school-going children from the potential supply of child labour. The opening up of special schools and provision of stipend and mid-day meals ${ }^{11}$ to children from the poorer families can attract children to schools. In the absence of any significant private efforts in the developing countries, the provision of free education solely rests upon the government and the extent of its efforts in this regard can be measured by the amount of subsidy on education. So higher the subsidy on education, $E$, the higher would be the free educational facilities and the related incentives to attract children from the poorer urban households and the larger would be the number of school-going children, $f(E)$. Thus an increase in $E$ lowers the actual supply of child labour, $L_{C}$, and vice versa. We also assume that the school-going children cannot undertake any part-time job.

The demand-supply equality condition for the intermediate good, $Y$, is given by

$$
\mathrm{a}_{\mathrm{YZ}} \mathrm{Z}=\mathrm{Y}
$$

There are nine endogenous variables in the system: $W_{C}, W_{\mathrm{b}}, r, P_{Y}, X, Y, Z, L_{C}, L_{U}$, which are solved from equations (1-9). This is an indecomposable system. Given $\overline{W_{X}}$ and $P_{X}, r$ can be determined from equation (1). Substituting the value of $r$ into equation (3), $P_{Y}$ is determined. $W_{Y}$ and $W_{C}$ can be obtained by solving equations

\footnotetext{
${ }^{11}$ This has been shown in appendix I.
} 
(2) and (7). Using (9), $X$ can be expressed as a function of $Y$. Inserting the expression for $X$ into (4), one can obtain an equation containing the two variables $Y$ and $L_{U}$. Also, using (5) and (8), another equation with $Y$ and $L_{U}$ is found. The equilibrium values of $Y$ and $L_{U}$ are obtained as functions of parameters of the system by solving these two equations simultaneously. Once $Y$ is known, $Z$ is found from equation (9). From the expression for $X$, the equilibrium level of $X$ is obtained. Finally, $L_{C}$ is found from (5) as $Y$ is known. It is easy to check $^{12}$ that the level of urban unemployment for adult labour is positive in migration equilibrium under the simple sufficient condition: $a_{\mathrm{LY}} \leq a_{\mathrm{CY}}$.

A pertinent question at this point is why urban unemployment of adult labour may exist particularly when the urban informal sector wage rate is flexible. Given the fixed coefficient nature of the production technologies in different sectors of the economy, the output composition does not depend on factor prices. It entirely depends on the factor endowments, technological and other parameters of the system. Sector Y produces a non-traded intermediary, which is solely used by sector Z. So, the demand for the informal sector's product (and hence its level of production) completely depends on the output of sector $\mathrm{Z}$ and the technological parameter, aYz. This together with another technological parameter, a $a_{L Y}$, ultimately determines the level of employment in the urban informal sector. Hence, unemployment ${ }^{13}$ for adult labour in this model arises due to the inadequacy of demand for the intermediary used in sector Z. Empirical evidence of simultaneous existence of the informal sector and open unemployment in the urban sector is available in Banerjee (1986) and Gandhi-Kingdon and Knight (2001). Theoretically, this aspect has been treated in Gupta $(1993,1994)$, Chaudhuri (2000) and Yabuuchi (2002).

\footnotetext{
${ }^{12}$ The education subsidy policy is undertaken in different countries in a number of ways. Among the most popular incentive schemes are school meal programs. In countries like Brazil, Egypt, South Africa and India mid-day meals are offered to poor children attending schools. However, as noted by Brown, Deardorff and Stern (2001), school-lunch programs themselves do not provide a sufficient incentive to draw children out of work and into school. As a result of the low financial value of the meal combined with the poor quality of schools, school-lunch programs cannot generally alter the poor parents' calculation of the value of school relative to work. Alternatively, in a few countries like Bangladesh and Mexico, governments have instituted cash stipends or in-kind gifts for children attending schools. Ravaillion and Wodon (1999) have found the Food-for-Education (FFE) program quite successful in keeping the children from poor families into schools in rural Bangladesh. However, the impact of this program on the incidence on child labour was not satisfactory. See also footnote 15 in this context.

${ }^{13}$ In a very special case, however, full employment of adult labour may occur depending on the parameter values of the system.
} 


\section{A. The effects of a rise in the subsidy on education or foreign capital inflow on the supply of child labour in the urban sector}

To analyze the impacts of any changes in the amounts of subsidy on education and inflow of foreign capital on the child labour market we proceed as follows.

Using (5) and (8) we can write

$$
a_{C Y} Y=a_{L Y} Y+L_{U}-f(E) .
$$

Totally differentiating equations (4), (8.1), (6) and (9) and solving by Cramer's rule, the following expressions can be derived.

$$
\begin{gathered}
\hat{X}=-\left(\lambda_{L U} / \Delta_{1}\right) \cdot\left[\left\{\lambda_{L Y}+\lambda_{L U}+\lambda_{L U}-(f(E) / L)\right\} \cdot \hat{K}+\left(\lambda_{K Y}+\lambda_{K Z}\right) f^{\prime}(.) \cdot E \cdot \hat{E}\right],(10 . \hat{Y}) \cdot\left(\lambda_{L U} / \Delta_{1}\right) \cdot\left[\lambda_{L X} \cdot K+\lambda_{K X} \cdot f(.) \cdot E \cdot \hat{E}\right] \\
\hat{Y}
\end{gathered}
$$

and,

$$
\begin{aligned}
\hat{L}_{U} & =\left(\lambda_{L X} / \Delta_{1}\right)\left[f^{\prime}(.) E\left(\lambda_{L Y}+\lambda_{L Z}\right)\left\{\left(\left(\lambda_{K Y}+\lambda_{L Z}\right) /\left(\lambda_{K X}+\lambda_{L Z}\right)\right)-\left(\lambda_{K X} / \lambda_{L X}\right)\right\} .\right. \\
& \left.\hat{E}+\left\{\lambda_{L U}-(f(E) / L)\right\} . K\right]
\end{aligned}
$$

where $\Delta_{l}=\lambda_{L U} \cdot \lambda_{L X \cdot}\left\{\lambda_{L Y}+\lambda_{L Z}+\lambda_{L U}-(f(E) / L)\right\} \cdot\left[\left\{\left(\lambda_{K Y}+\lambda_{K Z}\right) /\left(\lambda_{L Y}+\lambda_{L Z}+\lambda_{L U}\right.\right.\right.$ $\left.-(f(E) / L))\}-\left(\lambda_{K X} / \lambda_{L X}\right)\right]$.

As the urban sector as a whole is more capital-intensive than the rural sector we have $\left[\left\{\left(\lambda_{K Y}+\lambda_{K Z}\right) /\left(\lambda_{L Y}+\lambda_{L Z}+\lambda_{L U}-(f(E) / L)\right)\right\}>\left(\lambda_{K X} / \lambda_{L X}\right)\right]$, which implies that $\Delta_{1}>0$.

Now from (10.3) we find that $\hat{L}_{U}>0$ when $\hat{E}>0$ as $\left\{\left(\left(\lambda_{K Y}+\lambda_{K Z}\right) /\left(\lambda_{L Y}+\lambda_{L Z}\right)\right)\right.$-( $\left.\left(\lambda_{K X} / \lambda_{L X}\right)\right\}>0$ if the urban sector as a whole is more capital intensive than the rural sector. Also $\hat{L}_{U}>0$ when $\hat{K}>0$ if and only if $\lambda_{L U}>(f(E) / L)$. So the following proposition is imminent.

PROPOSITION 1: A policy of free education to the children in the urban sector raises the level of urban unemployment of adult labour. An inflow of foreign capital also leads to an increase in adult unemployment iff $\lambda_{L U}>(f(E) /$ $L)$.

The urban families whose adult members are either employed in the informal sector or remain unemployed are termed as the poor urban families. The number of such families, denoted, $L_{P}$, is given by 


$$
L_{P}=a_{L Y} Y+L_{U}
$$

Totally differentiating (11) and using (10.2) and (10.3), one can easily derive $\mathrm{e}^{14}$ the following expression.

$$
\begin{aligned}
& \left(L_{P} / L\right) \cdot \hat{L}_{P}=\hat{K} \cdot\left(\lambda_{L U} \cdot \lambda_{L X} \cdot L_{C} / L \cdot \Delta_{l}\right)+\hat{E} \cdot\left[( E \cdot \lambda _ { L U } \cdot f ^ { \prime } ( . ) / \Delta _ { l } ) \cdot \left[\lambda_{L Y} \cdot \lambda_{K X}\right.\right. \\
& \text { (+) } \quad(+)(+) \\
& \left.+\lambda_{L X} \cdot\left(\lambda_{L Y}+\lambda_{L Z}\right) \cdot\left\{\left(\lambda_{K Y}+\lambda_{K Z}\right) /\left(\lambda_{L Y}+\lambda_{L Z}\right)\right\}-\left(\lambda_{K X} / \lambda_{L X}\right)\right] . \\
& (+)
\end{aligned}
$$

So, from (12) it follows that $\hat{L}_{P}>0$ if $\hat{K}, \hat{E}>0$. However, $\hat{L}_{P}=0$ if $t$ falls or $P_{X}$ rises as $t$ and $P_{X}$ are not included in (12). This establishes the following corollary.

COROLLARY 1: An increase in education subsidy or an inflow of foreign capital raises the number of poor urban families. On the other hand, any reduction in the import tariff or an increase in the primary agricultural commodity cannot change it.

Intuition behind corollary 1 is fairly straightforward. Inflow of foreign capital and/or an increase in the education subsidy leads to an expansion of the urban sector as a whole (formal plus informal). The expected urban income for a rural migrant family rises, leading to more migration from the rural sector. However, the number of new jobs created in the urban formal sector always falls short of the number of newly migrated families to the urban sector. The consequence would be an increase in the number of poor families in this sector.

Now, differentiation of (5) yields

$$
\hat{L}_{c}=\hat{Y}
$$

Thus, from (10.2) and (5.1) it follows that

$$
\hat{L}_{C}=\left(\lambda_{L U} / \Delta_{I}\right)\left[\lambda_{L X} \hat{K}+\lambda_{K X} \cdot f^{\prime}(.) \cdot E \cdot \hat{E}\right] .
$$

So $\hat{L_{C}}>0$ when $\hat{E}$ and / or $\hat{K}>0 \quad\left(\right.$ as $\left.\Delta_{l}, f^{\prime}()>0.\right)$.

This establishes the following proposition.

PROPOSITION 2 : A policy of providing free education to children in the

\footnotetext{
${ }^{14}$ This has been derived in appendix II..
} 
urban sector and/or an inflow of foreign capital unambiguously accentuates the incidence of child labour in the urban area.

Propositions 1 and 2 can be intuitively explained as follows. A policy of providing free education to the urban children raises the number school-going children, which in turn temporarily lowers the supply of child labour in the urban sector. As a consequence, the urban informal sector that produces an intermediary for the formal sector contracts releasing capital. Now if the urban sector, as a whole is more capital intensive than the rural sector, both of the urban sectors would ultimately expand at the expense of the rural sector. But as child labour is an essential input in the urban informal sector its expansion implies an ultimate increase in the supply of child labour. This may seem to be puzzling when the supply of child labour decreased initially following an increase in the number of school-attending children. We should note that as the formal manufacturing sector expands, the expected income of a rural migrant family in the urban sector rises leading to more migration from the rural sector. This raises the level of adult unemployment in the urban sector as new migrants outnumber the new job opportunities. Children from these new migrant families add to the size of the child workforce in the urban sector, which outweighs the initial drop in their number resulting from an increase in the free educational opportunities. So the net effect would be an increase in the number of child workers in the urban sector ${ }^{15}$. However, this lowers the incidence of child labour in the rural sector as more and more adult workers along with their children are drawn from the rural sector to the urban sector and as the family size of each working family has been assumed to be the same and given exogenously across the families irrespective of the employment status of their adult members. On the other hand, an inflow of foreign capital leads to an expansion of the two urban sectors and a contraction of the rural sector due to Rybczynski effect. Expansion of the informal manufacturing sector implies an increase in the supply of child labour that comes from the newly migrated working families into the urban sector. However, given the fixedcoefficient production technologies, as the capital endowment of the economy has

\footnotetext{
${ }^{15}$ In this context, mention should be made of the empirical paper by Ravallion and Wodon (1999) who have found that the school enrollment subsidy reduced the incidence of child labor in Bangladesh. However, they have admitted that the magnitude of decline in the incidence of child labour as a proportion of the total amount of enrollment subsidy is insignificant. This is because parents are clearly substituting other uses of their children's time, so as to secure the current income gain from access to the program with modest impact on earnings from their children's work.
} 
risen in this case, the employment opportunities of the adult workers would increase relatively more compared to the education subsidy case. Thus the effect on the level of urban unemployment of adult labour is ambiguous. It increases if and only if $\lambda_{L U}>(f(E) / L)$.

\section{B. The effects of education subsidy and trade liberalization on the wage rate of child labour and welfare of the poorer section of the urban working families}

In this section of the paper, we are interested to study the effects of free education policy and different liberalized trade policies on the child wage rate and also on the welfare of the poorer section of the working families in the urban sector. The working families, in which the adult members are either unemployed or find employment only in the low wage-paying informal sector, constitute the poorer section of the urban families. The welfare of each family in this category of urban families, for the sake of analytical simplicity, is measured simply by the average income of these families although there are actually two sub-sections within the poorer section of families depending on the status of employment of their adult members.

The international trade scenario has undergone a drastic change after the conclusion of the multilateral agreement and the formation of the World Trade Organization (WTO) in the Uruguay round of discussions. The developing economies have dumped their inward oriented policies and strived to join the regime of liberalization so as to reap the benefits of a freer global trade. Radical measures are being adopted to reduce tariff barriers and completely remove nontariff barriers to ensure freer global trade not only in specialized manufacturing commodities but also in agricultural commodities. In most of the countries whether developing or developed, the agricultural sector is highly subsidized. Moreover, there are tariff and non-tariff barriers to free imports as well. If the results of reduced trade barriers and increased international competition uniformly hold across countries, whether developed or developing, the prices of the primary agricultural exports of the developing countries are expected to rise, possibly owing to the multilateral tariff reductions by the large trading countries and the consequent increase in their import demands. In the context of the present model, trade liberalization in agriculture implies an increase in the price of the export commodity, $P_{X}$. On the contrary, tariff reform in the case of manufacturing 
products means a reduction in the import tariff, $t$, on $Z$.

To analyze the effects of the trade reforms, after differentiating equations (1-3) and (7), using (4), (10.1) and (10.2) and solving by Cramer's rule we get ${ }^{16}$

$$
\begin{array}{r}
\hat{W}_{C}=\left(1 / \Delta_{2}\right) \cdot\left[W_{Y} \lambda_{L Y}\left(T \hat{t}-\mathrm{H} \hat{P}_{X}\right)+\theta_{L Y}(\mathrm{~A} \cdot \hat{K}+\mathrm{B} \cdot \hat{E}],\right. \\
(+) \quad(+)(+)
\end{array}
$$

and,

$$
\hat{W}_{Y}=\left(1 / \Delta_{2}\right) \cdot\left[-\theta_{\mathrm{CY}} \cdot(A \hat{K}+B \hat{E})-\mathrm{W}_{\mathrm{C} \cdot\left(1-\lambda_{\mathrm{LX}}\right)(\mathrm{T} . \hat{t}}-H \cdot \hat{P}_{X}\right],
$$

where,

$$
\Delta_{2}=-\left(W_{C} \cdot \theta_{L Y} / L\right) \cdot\left[a_{L Z} \cdot Z+f(E)\right]<0 \text {; }
$$

From (13), it is seen that $\hat{W}_{C}>0$ if $\hat{t}<0$ or $\hat{P}_{X}>0$ or $\hat{E}>0$. On the contrary, $\hat{W}_{C}<0$ if $\hat{K}>0$. This establishes the following proposition.

PROPOSITION 3: The wage rate of child labour in the urban sector rises if (i) the education subsidy increases; or if (ii) import tariff on the final manufacturing product falls; and if (iii) the price of the primary export commodity rises owing to worldwide liberalized trade policies in agriculture.

The total number of the poor families in the urban sector is $\left(a_{L Y} Y+L_{U}\right)$. Some of the adult members of these families find employment in the informal sector at the wage rate, $W_{\mathrm{Y}}$, while the others remain unemployed and earn nothing. A few of the children from these families go to schools and the rest work in the informal sector at the child wage rate, $W_{C}$. So the average income of these working families, $G$, is given by the following.

$$
G=\left[\left\{W_{Y \cdot} a_{L Y} Y+W_{C} \cdot L_{C}\right\} /\left\{a_{L Y} Y+L_{U}\right\}\right]=\left[\left\{Y .\left(a_{L Y} W_{Y}+a_{C Y} W_{C}\right)\right\} /\left(a_{L Y} Y+L_{U}\right)\right] .
$$

We should note that the total income of the urban poor families entirely comes from the urban informal sector. In $(15),\left(a_{L Y} W_{Y}+a_{C Y} W_{C}\right)$, is the share of adult and child labour in the value of production of the informal sector per unit.

As the price of the primary commodity, produced by the rural sector, $P_{X}$ rises,

${ }^{16}$ See appendix III for detailed derivations of equations (13) and (14). 
the rental on capital $r$ also rises as the rural sector wage rate, $\bar{W}_{X}$ is given, which in turn lowers the price of the product produced by the informal sector, $P_{Y}$, to satisfy the zero profitability condition. Again, a reduction of the import tariff, $t$ on the formal sector's product lowers $P_{Y}$ directly as $r$ is determined from the priceunit cost equality condition (equation 1) of the rural sector. In both of these cases, $\left(a_{L Y} W_{Y}+a_{C Y} W_{C}\right)$ falls (see equation (2)). $Y$ also does not change (see (10.2)). So, the aggregate income of the poor urban families falls. However, the number of urban poor families does not change (see corollary 1). The consequence would be a fall in the average income of the deprived families of the urban sector.

On the contrary, an increase in the amount of education subsidy and/or inflow of foreign capital leads to an expansion of both of the two urban sub-sectors, as the urban sector as a whole is more capital-intensive vis-a-vis the rural sector. The share of adult and child labour in the value of production of the informal sector per unit, $\left(a_{L Y} W_{Y}+a_{C Y} W_{C}\right)$, does not change. But the aggregate income of the urban sector poor families rises as $Y$ rises. On the other hand, the total number of poor families also rises (see corollary 1). The net effect on their average income must depend upon the relative increases of the two terms. It can be easily shown ${ }^{17}$ that in the case of foreign capital inflow the proportionate increase in their aggregate income would be greater than that of their family number. On the contrary, in the case of a hike in education subsidy the opposite will happen. Thus, the average income of the poor families in the urban sector rises due to foreign capital inflow but it falls owing to an education subsidy policy. So, we can now state the following proposition.

PROPOSITION 4: Trade reforms in the form of tariff reductions and/or increase in the price of the export commodity, and increases in subsidy on education lower the welfare of the urban poor families. On the contrary, the urban poor people experience an increase in their welfare owing to foreign capital inflows.

\section{Concluding Remarks}

In this paper we have examined the implications of a free education policy and liberalized trade policies on the child and adult labour markets in the urban

\footnotetext{
${ }^{17}$ This has been proved in appendix IV.
} 
sector and on the welfare of the poorer section of the urban working families in a three sector general equilibrium set-up with Harris-Todaro type unemployment of adult labour. Unemployment of adult labour exists in the migration equilibrium despite the presence of the urban informal sector that produces an internationally non-traded intermediate input for the formal sector using child labour along with adult labour and capital as inputs. We have shown that inflow of foreign capital in the economy and/or a free education policy may raise the supply of child labour in the urban sector by forcing rural workers to migrate to the urban sector with their children and accentuate the problem of urban unemployment of adult labour. Besides, trade reforms like tariff reductions on the urban final manufacturing product or rise in the price of the export commodity resulting from worldwide liberalized trade policies in agriculture and the education subsidy policy lowers the welfare of the run of the meal people of the urban sector while foreign capital inflow unambiguously improves their welfare.

There are a large number of assumptions embodied in the model, some of which are restrictive. Fixed-coefficient technologies have been assumed in all the three sectors of the economy. Otherwise, it becomes very difficult to derive straightforward analytical results. Also, the assumption that a child worker cannot migrate to the urban sector unless his/her guardian migrates is restrictive. Although, there is some empirical evidence in support of this assumption, it may not be the case in general. However, the limitations of these assumptions must be judged in the light of the contributions of the paper. The paper has derived some results that are counterintuitive to the conventional wisdom. For example, the conventional wisdom suggests that an improvement of the educational facilities would bring about a significant reduction in the incidence of child labour. Also, the proponents of the liberalized trade and investment policies advocate that the policies like tariff reforms and/or inflow of foreign capital in substantial amounts would definitely take the developing countries into higher growth orbits, the benefits of which would ultimately percolate down to the bottom rungs of the society and thus reduce poverty. A reduction in poverty, in turn, would exert a downward pressure on the incidence of child labour and urban unemployment of adult labour. The results of this paper can at least question the effectiveness of these policies as a general proposition. 


\section{Acknowledgements}

We are indebted to an anonymous referee of this journal for his/her constructive comments on an earlier version of the paper. However, the usual disclaimer applies.

Received 6 May 2001, Accepted 31 March 2002

\section{References}

Anti-slavery Reporter (1996): Child Labour and the Social Clause; Series VIII, 2(4), November, 6-7.

Banerjee, B. (1986) Rural to Urban Migration and the Urban Labour Market: A Case Study of Delhi, Himalaya Publishing House, Bombay.

Basu, K., Van, P.H. (1998) The Economics of Child Labour, American Economic Review, 88(3), 412-427.

Basu, K. (1999) Child Labour: Cause, Consequence, and Cure, with Remarks on International Labour Standards, Journal of Economic Literature, 37(September), 1083-1119.

Bedi, A.S., Garg, A. (2000) The Effectiveness of Private versus Public Schools: The Case of Indonesia, Journal of Development Economics, 61, 463-494.

Bose, A.N. (1978) Calcutta and Rural Bengal: Small Sector Symbiosis, New Delhi: Minerva Publications.

Brown, D.K., Deardorff, A.V., Stern, R.M. (2001) Child Labor: Theory, Evidence and Policy, Discussion Paper No. 474, Research Seminar in International economics, School of Public Policy, The University of Michigan.

Chandra, V., Khan, M.A. (1993) Foreign Investment in the Presence of an Informal Sector, Economica, 60, 79-103.

Chaudhuri, S. (2000) Rural-Urban Migration, Informal Sector, Urban Unemployment and Development Policies- A Theoretical Analysis, Review of Development Economics, 4(3), 353-364.

Dasgupta, P., Ray, D. (1990) Adapting to Undernourishment: The Biological Evidence and its Implications, in, The Political Economy of Hunger (Eds.) Dreze, J., Sen, A., Oxford: Clarendon Press.

Dessy, S.E. (2000) A Defense of Compulsive Measures against Child Labour, Journal of Development Economics, 62, 261-275.

Dreze, J., Mukherjee, A. (1989) Labour Contracts in Rural India, in The Balance between Industry and Agriculture in Economic Development (Ed.) Chakravarty, S., London: Macmillan.

Eswaran, M. (1996) Fertility, Literacy, and the Institution of Child Labour, CRESP Dicussion Paper: No. 36, The University of British Columbia. 
Gandhi-Kingdon, G., Knight, J. (2001) Unemployment in South Africa: The Nature of the Beast, Centre for the Study of African Economies, University of Oxford, WPS/200115.

Grinols, E. L. (1991) Unemployment and Foreign Capital: The Relative Opportunity Cost of Domestic Labour and Welfare, Economica, 57, 107-21.

Grootaert, C. (1998) Child Labour in Cote d'Ivoire: Incidence and Determinants, in The Policy Analysis of Child Labour: A Comparative Study (Eds.) Grootaert, C., Patrinos, H., World Bank, Washington.

Gupta, M.R. (1993) Rural-Urban Migration, Informal Sector and Development Policies:

A Theoretical Analysis, Journal of Development Economics, 45, 407-14.

Gupta, M.R. (1994) Duty-free Zone, Unemployment, and Welfare: A Note, Journal of Economics, 59(2), 217-236.

Gupta, M.R. (1997) Foreign Capital and Informal Sector: Comments on Chandra and Khan, Economica, 64, 353-63.

ILO. (1995) Child Labour in Nepal: An Overview and a Proposed Plan of Action. Geneva: ILO.

ILO. (1996) Economically Active Populations: Estimates and Projections, 1950-2010. Geneva: ILO.

Jimenez, E., Lockheed, M. (1995) Public and Private Secondary Education in Developing Countries: A Comparative Study, World Bank Discussion Paper, no. 309. The World Bank, Washington, DC.

Joshi, H., Joshi, V. (1976) Surplus Labour and The City: A Study of Bombay, New Delhi Oxford University Press.

Mohsin, N. (1996) Counting and Accounting of Child Labour in Unorganized Sectors, Labour and Development, 1(2), Jan-June.

Osmani, S.R. (1990) Nutrition and the Economics of Food: Implications of some Recent Controversies, in The Political Economy of Hunger (Eds.) Dreze, J., Sen, A., Oxford: Clarendon Press.

Osmani, S.R. (1991) Wage Determination in Rural Labour Markets: The Theory of Implicit Cooperation, Journal of Development Economics, 34, 3-23.

Papola, T. S. (1981) Urban Informal Sector in a Developing Economy, New Delhi Vikas Publishing House.

Ravallion, M., Wodon, Q. (1999) Does Child Labor Displace Schooling? Evidence on Behavioral Responses to an Enrollment Subsidy, paper presented at the Annual Conference of the Royal Economic Society 1999, at the University of Nottingham, England.

Romatet, E. (1983) Calcutta's Informal Sector: Theory and Reality, Economic and Political Weekly, 18 (50), 2115-28.

Rudra, A. (1981) Indian Agricultural Economics: Myths and Realities, New Delhi: Allied Publishers.

Yabuuchi, S. (2002) Illegal Immigration, Informal Sector and Development Policies in a Dual Economy, Arthaniti, 1(1-2). 


\section{Appendix I}

From (9) one can write

$$
Z=\left(Y / a_{y z}\right)
$$

Using (A.1) and (6) one can sole

$$
X=\left(1 / a_{K Y}\right)\left[K-Y\left(a_{K Y}+a_{K Z} / a_{Y Z}\right)\right]
$$

Insertion of the expression for $\mathrm{X}$ into (4) and use of (A.1) yield

$$
Y\left(a_{L Y}+\left(a_{L Z} / a_{Y Z}\right)-\left\{\left(a_{L Y} /(1+\beta) a_{K Y}\right)\left(a_{K Y}+a_{K Z} / a_{Y Z}\right)\right\}\right]+L_{U}=L-\left\{a_{L X} K /(1+\beta) a_{K Y}\right\}
$$

Using (5) and (8) one may obtain

$$
Y\left(a_{L Y}-a_{C Y}\right)+L_{U}=f(E)
$$

Subtracting (A.4) from (A.3) and after simplification we get

$$
Y=\left[K\left\{(L / K)-\left(a_{L X} /(1+\beta) a_{K Y}\right)\right\}-f(E) /\left[a_{C Y}+\left(a_{L Z} / a_{Y Z}\right)-\left(a_{L X} /(1+\beta) a_{K X}\right)\left(a_{K Y}+\left(a_{K Z} / a_{Y Z}\right)\right.\right.\right.
$$

We should note that $\left(a_{L X} /(1+\beta) a_{K Y}\right)$ denotes the adult labour-capital ratio in the rural sector and this must be greater than the overall adult labour-capital ratio, $(L$ $K)$ of the entire economy in a Harris-Todaro framework. So, $\left\{(L / K)-\left(a_{L X} /\right.\right.$ $\left.\left.(1+\beta) a_{K Y}\right)\right\}<0$. Thus, assuming that $Y>0$ in equilibrium from (A.5) it follows that

$$
\left[a_{C Y}+\left(a_{L Z} / a_{Y Z}\right)-\left(a_{L X} /(1+\beta) a_{K X}\right)\left(a_{K Y}+\left(a_{K Z} / a_{Y Z}\right)\right]<0 .\right.
$$

Now using (A.4) and (A.5) one can write

$$
\begin{aligned}
& L_{U}=f(E)-\left(a_{L Y}-a_{C Y}\right)\left[K\left\{(L / K)-\left(a_{L X} /(1+\beta) a_{K X}\right)\right\}-f(E)\right] /\left[a_{C Y}+\left(a_{L Z} / a_{Y Z}\right)-\left(a_{L X} /\right.\right. \\
& \left.(1+\beta) a_{K X}\right)\left(a_{K Y}+\left(a_{K Z} / a_{Y Z}\right)\right]
\end{aligned}
$$

After simplification this reduces to the following.

$$
\begin{gathered}
L_{U}=\left[\left[f(E) / a_{Y Z} \cdot\left\{a_{C Y}+\left(a_{L Z} / a_{Y Z}\right)-\left(a_{L X} /(1+\beta) a_{K X}\right)\left(a_{K Y}+\left(a_{K Z} / a_{Y Z}\right)\right)\right\}\right] \cdot\left[a_{L Z}+a_{Y Z} a_{L Y}\right)-\right. \\
\left.\left.\left(a_{L X} /(1+\beta) a_{K X}\right)\left(a_{K Z}+a_{Y Z} a_{K Y}\right)\right]\right]-\left[\left[a_{L Y}-a_{C Y}\right) K\left\{(L / K)-\left(a_{L X} /(1+\beta) a_{K X}\right)\right\}\right] /\left[a_{C Y}+\left(a_{L Z} /\right.\right. \\
\left.\left.\left.a_{Y Z}\right)-\left(a_{L X} /(1+\beta) a_{K X}\right)\left(a_{K Y}+\left(a_{K Z} / a_{Y Z}\right)\right)\right]\right]
\end{gathered}
$$

Following the Chandra-Khan (1993), we assume that the urban sector as whole is more capital intensive relative to the rural sector, i.e. $\left(a_{K X} /(1+\beta) a_{L X}\right)<$ $\left\{\left(a_{K Z}+a_{Y Z} a_{K Y}\right) /\left(a_{L Z}+a_{Y Z} \cdot a_{L Y}+L_{U} / L\right)\right\}$. From this it follows that $\left[\left(a_{L Z}+a_{Y Z} \cdot a_{L Y}\right)-\left\{\left(a_{L X}\right]\right.\right.$ $\left.\left.\left.(1+\beta) a_{K Y}\right) \cdot\left(a_{K Z}+a_{Y Z} \cdot a_{K Y}\right)\right\}\right]<0\left(\right.$ as $\left.L_{U}>0\right)$ 


$$
L_{U}>0
$$

So, using (A.5.1), (A.6.1) and the condition that $\left\{(L / K)-\left(a_{L X} /(1+\beta) a_{K X}\right)\right\}<0$, from (A.6) it follows that

$$
L_{U}>0 \text { if } a_{L Y} \leq a_{C Y}
$$

However, in the absence of the subsidy on education $f(E)=0$, no children from the urban poor families go to school. In this case,

$$
L_{U}>0 \text { iff } a_{L Y}<a_{C Y} \text { when } f(E)=0 .
$$

\section{Appendix II}

Totally differentiating equation (11) one gets the following expression.

$$
d L_{P}=a_{L Y} d Y+d L_{U}
$$

or, $L_{P} \hat{L}_{P}=a_{L Y} Y \cdot(d Y / Y)+L_{U} \cdot\left(d L_{U} / L_{U}\right)$

or, $\left(L_{P} / L\right) \cdot \hat{L}_{P}=\lambda_{L Y} \hat{Y}+\lambda_{L U} \hat{L}_{U}$.

After inserting the expressions for $\hat{Y}$ and $\hat{L}_{U}$ from (10.2) and (10.3), it becomes

$$
\begin{aligned}
& \left(L_{P} / L\right) \cdot \hat{L}_{P}=\lambda_{L Y}\left(\lambda_{L U} / \Delta_{1}\right) \cdot\left[\lambda_{L X}+\lambda_{K X} \cdot f^{\prime}(.) \cdot E\left(\lambda_{L Y}+\lambda_{L Z}\right)\left\{\left(\left(\lambda_{K Y}+\lambda_{K Z}\right) /\left(\lambda_{L Y}+\lambda_{L Z}\right)\right)-\right.\right. \\
& \left.\left.\left(\lambda_{K X} / \lambda_{L X}\right)\right\} \cdot \hat{E}+\left\{\lambda_{L U^{\prime}}-(f(E) / L)\right\} \cdot K\right]=\left(\lambda_{L U} \cdot \lambda_{L X} / \Delta_{1}\right) \cdot\left[\lambda_{L Y}+\lambda_{L U}(f(E) / L)\right] . \hat{K}+\left(\lambda_{L U} \cdot f^{\prime}(.) \cdot E /\right. \\
& \left.\Delta_{1}\right) \cdot\left(\lambda_{L Y} \lambda_{K X}+\lambda_{L X \cdot} \cdot\left(\lambda_{L Y}+\lambda_{L Z}\right) \cdot\left\{\left(\left(\lambda_{K Y}+\lambda_{K Z}\right) /\left(\lambda_{L Y}+\lambda_{L Z}\right)\right)-\left(\lambda_{K X} / \lambda_{L X}\right)\right\}\right] . \hat{E}
\end{aligned}
$$

With the help of (8) it becomes

$$
\begin{aligned}
\left(L_{P} / L\right) \cdot \hat{L_{P}} & =\hat{K} \cdot\left(\lambda_{L U} \cdot \lambda_{L X} \cdot L_{C} / L \cdot \Delta_{1}\right)+\hat{E} \cdot\left[( E \cdot \lambda _ { L U } \cdot f ^ { \prime } ( . ) / \Delta _ { 1 } ) \cdot \left[\lambda_{L Y} \cdot \lambda_{K X}\right.\right. \\
& \left.+\lambda_{L X} \cdot\left(\lambda_{L Y}+\lambda_{L Z}\right) \cdot\left\{\left(\lambda_{K Y}+\lambda_{K Z}\right) /\left(\lambda_{L Y}+\lambda_{L Z}\right)\right\}-\left(\lambda_{K X} / \lambda_{L X}\right)\right] .
\end{aligned}
$$

\section{Appendix III}

Total differentiation of equations (1-3) yields 


$$
\begin{gathered}
\theta_{K X} \hat{r}=\hat{P}_{X,} \\
\theta_{C Y} \hat{W}_{C}+\theta_{K Y} \hat{W}_{Y}+\theta_{K Y} \hat{r}=\hat{P}_{Y,} \\
\theta_{Y Z} \hat{P}_{Y}+\theta_{K Z} \hat{r}=\hat{t}(t / 1+t),
\end{gathered}
$$

where, the circum flex denotes proportionate change and $\theta_{\mathrm{ji}}$ is the share of the $j^{\text {th }}$ input in the total value of production of the $i^{\text {th }}$ commodity for $j=L, L_{C}, K$ and $i=X, Y, Z$.

From equation (A.7.1) one can write $\hat{r}=\hat{P}_{X}\left(1 / \theta_{\mathrm{KX}}\right)$.

Substitution of $\hat{r}$ into equation (A.7.3) yields

$$
\hat{P}_{Y}=\hat{t}\left\{\mathrm{t} / \theta_{\mathrm{YZ}}(1+\mathrm{t})\right\}-\hat{P}_{X}\left(\theta_{\mathrm{KZ}} / \theta_{\mathrm{YZ}} \theta_{\mathrm{KX}}\right) .
$$

After substituting $\hat{r}$ and $\hat{P}_{Y}$ into equation (A.7.2), we get

$$
\begin{aligned}
& \theta_{\mathrm{CY}} \hat{W}_{C}+\theta_{\mathrm{LY}} \hat{W}_{Y}+\hat{P}_{X}\left(\theta_{\mathrm{KY}} / \theta_{\mathrm{KX}}\right)=\hat{t}\left\{\mathrm{t} / \theta_{\mathrm{YZ}}(1+\mathrm{t})\right\} \hat{P}_{X}\left(\theta_{\mathrm{KZ}} / \theta_{\mathrm{YZ}} \theta_{\mathrm{KX}}\right) \\
& \text { or, } \theta_{\mathrm{CY}} \hat{W}_{C}+\theta_{\mathrm{LY}} \hat{W}_{Y}=\hat{t}\left\{\mathrm{t} / \theta_{\mathrm{YZ}}(1+\mathrm{t})\right\}-\hat{P}_{X}\left[\left\{\left(\theta_{\mathrm{KZ}} / \theta_{\mathrm{YZ}}\right)+\theta_{\mathrm{KY}}\right\} / \theta_{\mathrm{KX}}\right] \\
& =T \hat{t}-H \hat{P}_{X},
\end{aligned}
$$

where $T=t /(1+t) \cdot \theta_{Y Z}>0 ; H=\left(1 / \theta_{\mathrm{KX}}\right) \cdot\left[\theta_{\mathrm{KY}}+\left(\theta_{\mathrm{KZ}} / \theta_{\mathrm{YZ}}\right)\right]>0$.

Using (4), equation (7) can be rewritten as

$$
W_{Y} a_{L Y} Y+\bar{W}_{Z} a_{L Z} Z=\left[\left\{\bar{W}_{X}(1+\beta)-W_{C}\right\}\left\{L-a_{L X} X /(1+\beta)\right\}\right] .
$$

Totally differentiating equation (A.9) we obtain $\mathrm{a}_{\mathrm{LY}} \mathrm{YdW} Y+\mathrm{a}_{\mathrm{LY}} \mathrm{W}_{\mathrm{Y}} \mathrm{dY}+\bar{W}_{Z} \mathrm{a}_{\mathrm{LZ}} \mathrm{dZ}=-\left\{\bar{W}_{X}(1+\beta)-\mathrm{W}_{\mathrm{C}}\right\}\left\{\mathrm{a}_{\mathrm{LX}} /(1+\beta)\right\} d X-\left\{\mathrm{L}-\mathrm{a}_{\mathrm{LX}} \mathrm{X} /\right.$ $(1+\beta)\} \mathrm{dW}_{\mathrm{C}}$

$$
\begin{gathered}
\text { or, } W_{C \cdot} \cdot\left\{L-\left(a_{L X} \cdot X /(1+\beta)\right)\right\} \hat{W}_{C}++a_{L Y} Y \cdot W_{Y} \hat{W}_{Y}=-\left\{\bar{W}_{X}(1+\beta)-\mathrm{W}_{C}\right\} \cdot\left(a_{L X} X /(1+\beta) \cdot \hat{X}\right. \\
-\left[a_{L Y} Y \cdot W_{Y}+\bar{W}_{Z} \cdot a_{L Z} \cdot Z\right] \cdot \hat{Y}(\text { since from }(9 \cdot 1), \hat{Y}=\hat{Z}) \\
=-\left\{\bar{W}_{X}(1+\beta)-\mathrm{W}_{\mathrm{C}}\right\}\left[\left\{a_{L X} \cdot X /(1+\beta\} \cdot \hat{X}+\begin{array}{r}
\left\{L-\left(a_{L X} \cdot X /(1+\beta)\right\} . \hat{Y}\right] \\
\text { (using equations (A.9) and (4)) }
\end{array}\right.\right.
\end{gathered}
$$

Dividing both sides by $L$ we get

$$
\mathrm{W}_{\mathrm{C}} \cdot\left(1-\lambda_{L X}\right) \cdot \hat{W}_{C}+\lambda_{\mathrm{LY}} \mathrm{W}_{\mathrm{Y}} \cdot \hat{W}_{Y}=-\left\{\bar{W}_{X}(1+\beta)-\mathrm{W}_{\mathrm{C}}\right\} \cdot\left[\lambda_{L X} \cdot \hat{X}+\left(1-\lambda_{L X}\right) \cdot \hat{Y}\right]
$$

After inserting the values of $\hat{X}$ and $\hat{Y}$ from (10.1) and (10.2) the above 
expression becomes

$$
\begin{aligned}
& \mathrm{W}_{\mathrm{C} \cdot} \cdot\left(1-\lambda_{L X}\right) \cdot \hat{W}_{C}+\lambda_{L Y} W_{Y} \cdot \hat{W}_{Y}=-\left\{\bar{W}_{X}(1+\beta)-\mathrm{W}_{\mathrm{C}}\right\} \cdot\left(\lambda_{L U} / \Delta_{1}\right) \cdot\left[( 1 - \lambda _ { L X } ) \cdot \left\{\lambda_{L X} \cdot \hat{K}+\right.\right. \\
& \left.\left.\lambda_{K X} \cdot f^{\prime} \cdot E \cdot \hat{E}\right\}-\hat{K} \cdot \lambda_{L X \cdot}\left\{1-\lambda_{L X^{-}}(f(E) / L)\right\}-\lambda_{L X} \cdot\left(1-\lambda_{K X}\right) \cdot f^{\prime} \cdot E \cdot \hat{E}\right]
\end{aligned}
$$

After a little manipulation this reduces to

$\mathrm{W}_{\mathrm{C}} \cdot\left(1-\lambda_{L X}\right) \cdot \hat{W}_{C}+\lambda_{L Y} W_{Y} \cdot \hat{W}_{Y}=-\left\{\bar{W}_{X}(1+\beta)-\mathrm{W}_{\mathrm{C}}\right\} \cdot\left(\lambda_{L U} / \Delta_{1}\right) \cdot\left[\left\{\lambda_{L X} \cdot(f(E) / L)\right\} \cdot \hat{K}+\right.$ $\left.\left\{f^{\prime} . E \cdot\left(\lambda_{K X}-\lambda_{L X}\right) \cdot \hat{E}\right\}\right]$

or, $\quad W_{C}\left(1-\lambda_{\mathrm{LX}}\right) \hat{W}_{C}+W_{Y} \cdot \lambda_{L Y} \hat{W}_{Y}=-A \cdot \hat{K}-B \cdot \hat{E}$

where, $A=\left[\left\{\hat{W}_{X} \cdot(1+\beta)-\left(\mathrm{W}_{\mathrm{C}}\right\} \cdot\left(\lambda_{L U} / \Delta_{1}\right) \cdot \lambda_{L X} \cdot(f(E) / L)\right]>0\right.$;

$$
(+) \quad(+)
$$

and, $B=\left[\left\{\hat{W}_{X} \cdot(1+\beta)-W_{C}\right\} \cdot\left(\lambda_{L U} / \Delta_{1}\right) \cdot f^{\prime} \cdot E \cdot\left(\lambda_{K X}-\lambda_{L X}\right)<0\right.$.
$(+)$
$(+)(+)$
$(-)$

We should note that $\left(\Delta_{1}>0\right.$ and $\lambda_{K X}<\lambda_{L X}$ since it is assumed that the urban sector as a whole is more capital-intensive than the rural sector, in accordance with the Chandra-Khan capital-intensity condition with $L_{U}>0$ i.e. $\left(a_{K Y} \cdot(1+\beta) / a_{L X}\right)<$ $\left\{\left(a_{K Z}+a_{Y Z} \cdot a_{K Y}\right) /\left(a_{L Z}+a_{Y Z} \cdot a_{L Y}+L_{U} / L\right)\right\}$

Solving (A.8) and (A.10) by Cramer's rule, we get

$$
\hat{W}_{C}=\left(1 / \Delta_{2}\right) \cdot\left[W_{Y} \lambda_{L Y}\left(\mathrm{~T} \hat{t}-\mathrm{H} \hat{P}_{X}\right)+\theta_{L Y}(A \cdot \hat{K}+\mathrm{B} \hat{E})\right],
$$

and,

$$
\hat{W}_{Y}=(1 / \Delta 2) \cdot\left[-\theta_{C Y}(A \cdot \hat{K}+\mathrm{B} \cdot E)-W_{C \cdot}\left(1-\lambda_{L X}\right)\left(\mathrm{T} \cdot \hat{t}-\mathrm{H} \cdot \hat{P}_{X}\right)\right],
$$

where,

$$
\begin{aligned}
& \Delta_{2}=W_{Y} \lambda_{L Y} \theta_{C Y}-\mathrm{W}_{\mathrm{C} \cdot}\left(1-\lambda_{L X}\right) \cdot \theta_{L Y} \\
& =\left(W_{Y} \cdot \mathrm{W}_{\mathrm{C}} \cdot \mathrm{a}_{\mathrm{LY}} / P_{Y} L\right)\left[L_{C}-L+\left\{\left(a_{L X \cdot \mathrm{X}}\right) /(1+\beta)\right\}\right] \\
& =\left(W_{C} \cdot \theta_{L Y} / \mathrm{L}\right) \cdot\left[a_{L Y} Y+L_{U}-f(E)+\left\{a_{L X} \cdot X /(1+\beta)\right\}-L\right] \quad \text { (using (8)) } \\
& =-\left(W_{C} \cdot \theta_{L Y} / L\right) \cdot\left[a_{L Z} \cdot Z+f(E)\right] \\
& \text { (obtained after using (4)) }
\end{aligned}
$$


$<0$.

\section{Appendix IV}

With the help of (2) and (5), the expression (15) may be rewritten as

$$
G=\left[\left\{P_{Y}-r \cdot a_{K Y}\right\} /\left\{a_{L Y}+\left(L_{U} / Y\right)\right\}\right]=\left\{M /\left(a_{L Y}+N\right)\right\},
$$

where, $M=\left\{P_{Y}-r \cdot a_{K Y}\right\}$; and, $N=\left(L_{U} / Y\right)$.

Since the $a_{i j}$ s are given owing to the assumption of fixed-coefficient technology the effects of the policy changes on $G$ must depend upon the consequent changes on $r, P_{Y}$ and $\left(L_{U} / Y\right)$. Differentiating $M$ and $N$ and using (A.7.4), (A.7.5), (10.2) and (10.3) we get the following expressions.

$$
\begin{gathered}
\text { M. } \hat{M}=\left\{P_{Y} t / \theta_{Y Z}(1+t)\right\} . \hat{t}-\left\{\left(\theta_{K Z} / \theta_{Y Z}\right)+\theta_{K Y}\right\} .\left(P_{Y} / \theta_{K X}\right) \cdot \hat{P}_{X}, \\
\text { and, N. } \hat{N}=\left\{f^{\prime}(.) \cdot E / \Delta_{1}\right\} \cdot\left[\lambda_{L X \cdot} \cdot\left(\lambda_{K Y}+\lambda_{K Z}\right)-\lambda_{K X} \cdot\left(\lambda_{L Y}+\lambda_{L Z}+\lambda_{L U}\right)\right] . \hat{E} \\
(+) \quad(+) \quad(+) \\
-\left\{\lambda_{L X X} \cdot(E) / L \cdot \Delta_{1}\right\} . \hat{K} \\
(+)
\end{gathered}
$$

(Note that $\Delta_{1}>0$ and $\lambda_{L X .} \cdot\left(\lambda_{K Y}+\lambda_{K Z}\right)>\lambda_{K X} \cdot\left(\lambda_{L Y}+\lambda_{L Z}+\lambda_{L U}\right)$ as the urban sector as a whole is more capital-intensive than the rural sector.).

Now if $\hat{P}_{X}>0$ or $\hat{t}<0$ from (A.12) it follows that $\hat{M}<0$. From (A.11) it now follows that $G$ falls when $P_{X}$ rises or t falls. Again, if $\hat{K}>0$ from (A.13) it follows that $\hat{N}<0$. So $G$ rises as $K$ rises. On the contrary, $\hat{N}>0$ when $\hat{E}>0$. Thus, $G$ falls if $E$ goes up. 